\title{
Second-Best Instruments for Near-Term Climate Policy: Intensity Targets vs. the Safety Valve Mort Webster ${ }^{1}$, Ian Sue Wing ${ }^{2}$, Lisa Jakobovits ${ }^{1}$ \\ ${ }^{1}$ MIT Joint Program for the Science and Policy of Global Change, Massachusetts Institute of Technology \\ ${ }^{2}$ Dept. of Geography \& Environment, Boston University
}

Keywords: Uncertainty, climate change, instrument choice, safety valve, intensity target.

\begin{abstract}
Current proposals for greenhouse gas emissions regulations in the United States mainly take the form of emissions caps with tradable permits. Since Weitzman's (1974) study of prices vs. quantities, economic theory predicts that a price instrument is superior under uncertainty in the case of stock pollutants. Given the general belief in the political infeasibility of a carbon tax, there has been recent interest in two other policy instrument designs: hybrid policies and intensity targets. We extend the Weitzman model to derive an analytical expression for the expected net benefits of a hybrid instrument under uncertainty. We compare this expression to one developed by Newell and Pizer (2006) for an intensity target, and show the theoretical minimum correlation between GDP and emissions required for an intensity target to be preferred over a hybrid. We test the predictions by performing Monte Carlo simulation on a computable general equilibrium model of the U.S. economy. The results are similar, and we show with the numerical model that when marginal abatement costs are non-linear, an even higher correlation is required for an intensity target to be preferred over a safety valve.
\end{abstract}




\section{Introduction}

As many countries prepare to begin their implementation of the Kyoto Protocol (Ellerman and Buchner, 2006) and the United States begins more serious discussions of domestic climate policy (Paltsev et al, 2007) and potential future international frameworks (Stolberg, 2007), interest in alternative regulatory instruments for greenhouse gas emissions is increasing. Because greenhouse gases are stock pollutants, we expect their marginal benefits for a given decision period (1-5 years) to have a negligible slope. The seminal work by Weitzman $(1974,1978)$ and extended by Pizer (2002) and Newell and Pizer (2006) showed that under cost uncertainty and relatively flat marginal damages that a carbon tax equal to the expected marginal benefit is superior to the optimal emissions cap.

Given the experience with an attempt at a BTU tax under the Clinton Administration, the prevailing view is that a carbon tax is politically infeasible, at least in the United States (Washington Post, 2007; Newell and Pizer, 2006). This political constraint on instrument choice, combined with the significant uncertainty in abatement costs under a pure quantity instrument, has generated interest in two suboptimal instruments that are superior to quantity instruments in the presence of uncertainty: a hybrid or safety valve instrument, and an indexed cap or intensity target. The safety valve is one in which an emissions cap is set with tradable permits allocated, but if the permit price exceeds some set trigger price, an unlimited number of permits are auctioned off at the trigger price (Pizer 2005; Jacoby and Ellerman, 2005), thus reverting to a carbon tax. An indexed cap is one in which the quantity of permits allocated is set not to an absolute emissions target, but rather is determined relative to some other measurable 
quantity, for example GDP, which is correlated with emissions (Newell and Pizer, 2006; Ellerman and Sue Wing, 2003; Sue Wing et al., 2006).

Weitzman (1974) originally developed an expression for the relative advantage of prices versus quantity instruments for a pollution externality in the presence of uncertainty. Pizer (2002) showed that the safety valve for a stock externality under uncertainty is superior to a pure quantity instrument and as good as or better than a pure price instrument. There have been several studies of the behavior of an indexed cap or intensity target under uncertainty and its relative advantages and disadvantages to quantity and price instruments, including Newell and Pizer (2006), Quirion (2005), and Sue Wing et al (2006). In general, the advantages of index cap have been shown in the above studies to be a function of the correlation between emissions and the indexed quantity, as well as the relative slopes of marginal costs and benefits, and the variance of the uncertainty. However, there have been no direct comparisons in the literature between indexed caps and hybrid instruments. Since this choice between second-best instruments is one key element in the current debate (Paltsev et al, 2007), it is useful to demonstrate both theoretically and empirically when indexed caps should be preferred to hybrid instruments or the reverse.

In this study, we develop a rule that indicates when indexed caps will be the preferred instrument for regulating a stock pollutant under uncertainty, in terms of expected net benefits, to a safety valve instrument. We use the theoretical model of an externality developed by Weitzman (1974) and extended by Newell and Pizer (2006), which we present in Section 2. In Section 3, we extend this model to first show the optimal trigger price for a hybrid instrument, and then derive an expression for the 
expected net benefits under this optimal hybrid policy. We then compare this result to the expression derived by Newell and Pizer for an indexed cap, and derive a general rule for when the indexed cap is preferred over the safety valve. In Section 4, we illustrate the results by conducting uncertainty analysis on a static computable general equilibrium (CGE) model of the US economy, and show that with the non-linear marginal costs of the CGE model that the hybrid is even more preferable. Section 5 gives conclusions and discussion.

\section{Model of Pollution Externality}

We begin by reviewing the basic Weitzman (1974) model and results. Benefits and costs are modeled as second order Taylor Series expansions about the expected optimal abatement quantity target $q^{*}$. Costs and benefits, respectively, are defined as:

$$
\begin{aligned}
& C(q)=c_{0}+\left(c_{1}-\theta_{c}\right)\left(q-q^{*}\right)+\frac{c_{2}}{2}\left(q-q^{*}\right)^{2} \\
& B(q)=b_{0}+b_{1}\left(q-q^{*}\right)-\frac{b_{2}}{2}\left(q-q^{*}\right)^{2}
\end{aligned}
$$

We assume that $c_{2}>0$ and $b_{2} \geq 0$; i.e., costs are strictly convex and benefits are weakly concave. $\theta_{c}$ is a random shock to costs with expectation 0 and variance $\sigma_{c}^{2}$. As in Newell and Pizer, we define $\theta_{c}$ such that a positive shock reduces the marginal cost of producing $q$.

Taking the derivative of net benefits, taking the expectation, and setting to zero, we obtain the conditions for the optimal quantity:

$$
b_{1}-b_{2}\left(q-q^{*}\right)=c_{1}+c_{2}\left(q-q^{*}\right)
$$


The optimal abatement will be $q^{*}$ if and only if $b_{1}=c_{1}$. Since the expansion is done around the optimal point, marginal costs equal marginal benefits at that emissions level. The expected net benefits with an emission cap of $q=q^{*}$ is:

$$
E\left\{N B_{q}\right\}=b_{0}-c_{0}
$$

For the price instrument, emissions would be reduced up to where marginal costs equal the tax:

$$
p=c_{1}-\theta+c_{2}\left(q-q^{*}\right)
$$

Rearranging, emissions under the tax is

$$
q(\theta)=q^{*}+\frac{p-c_{1}+\theta}{c_{2}}
$$

Because the optimal tax is equal to the marginal benefits, which in turn is equal to the marginal cost, $p^{*}=b_{1}=c_{1}$,

$$
q(\theta)=q^{*}+\frac{\theta}{c_{2}}
$$

Substituting (7) into the net benefits and taking the expectation yields:

$$
E\left\{N B_{p}\right\}=b_{0}-c_{0}+\frac{\left(c_{2}-b_{2}\right) \sigma^{2}}{2 c_{2}^{2}}
$$

This is the classic result from Weitzman (1974). The net gain from a price instrument relative to a quantity instrument is:

(9) $\Delta_{p-q}=\frac{\left(c_{2}-b_{2}\right) \sigma^{2}}{2 c_{2}^{2}}$

When the slope of the marginal costs exceeds the slope of the marginal benefits, a price instrument is preferred. 


\section{Second-Best instruments for Cost-Containment}

We now extend this model to represent a hybrid instrument or safety valve. We will first solve for the optimal trigger price, given an emissions cap. We then derive the expression for the expected net benefits of the safety valve. Finally, we derive the expressions for the net gain from an intensity target relative to a safety valve, and show the general conditions under which each instrument is preferred.

\section{a. Optimal Design of Hybrid Instrument}

A hybrid regulatory instrument consists of both a quantity and a price instrument. An emissions cap is set, just as in a pure quantity instrument, and emissions permits are allocated among emitters, which they are allowed to trade. In addition, the regulatory agency will sell additional permits at some trigger price $p$, for as many permits as are necessary. Thus $p$ establishes a ceiling on the permit price; it can never rise above this level. If the permit price is below $p$, a rational agent will either buy a permit from the market or abate, and the regulation behaves like a quantity regime. If the emissions limit is stringent enough for the permit price to rise above $p$, agents will buy additional permits from the government and, for the purposes of calculating net benefits, the regulation behaves like a price instrument.

The resulting net benefits from the hybrid instrument, as for quantity and price instruments, depend critically on the choice of the emissions limit and the trigger price. As in Weitzman (1974) and in Newell and Pizer (2006), we wish to assume optimal choices of these design variables. However, there is immediately a difficulty: we know from the Weitzman result, as summarized above, that the optimal hybrid instrument 
consists of an emissions limit of zero (i.e., no allowances) and an optimal trigger price equal to the optimal pure tax. A hybrid instrument with a non-zero emissions limit is inherently a second-best instrument compared with a pure price instrument, but may be necessary when a price instrument is not politically feasible. We therefore proceed for the remainder of this paper under the assumptions that 1) a pure emissions tax is not feasible, and 2) the emissions limit for a hybrid instrument will be given as an outcome of some political process. The question we address here is under what conditions is a hybrid instrument with some non-zero cap preferable to an intensity target with an equivalent cap.

The first step is to solve for the optimal trigger price under a non-zero emissions cap. We begin with a simplified version of the model from section 2 to motivate this result. Assume that the cost uncertainty $\theta_{c}$ is a two-state discrete distribution:

$$
\begin{aligned}
& \theta_{L}=\bar{\theta}-\delta \quad \operatorname{Pr}=0.5 \\
& \theta_{H}=\bar{\theta}+\delta \quad \operatorname{Pr}=0.5 \\
& E\{\theta\}=\bar{\theta}=0 \\
& V A R\{\theta\}=\sigma^{2}=\delta^{2}
\end{aligned}
$$

When $\theta=\theta_{L}$, the price instrument will be in effect, since the marginal cost is higher than the expected value. Conversely, when $\theta=\theta_{H}$, marginal costs are lower, and the quantity instrument will be in effect.

The second assumption is that the emissions limit $q^{*}$ under the hybrid instrument is the optimal quantity under the pure quantity instrument. When $\theta=\theta_{H}$ and the cap is in effect, the optimal emissions will be: $q=q^{*}$. When $\theta=\theta_{L}$ and the price instrument is in effect, the optimal emissions will be: 


$$
q=q^{*}+\frac{p-c_{1}+\theta_{L}}{c_{2}}=q^{*}+\frac{p-c_{1}-\delta}{c_{2}} .
$$

The expected net benefits of the hybrid instrument is:

$$
\begin{aligned}
E\left\{N B_{s v}\right\} & =\frac{1}{2}\left[b_{0}-c_{0}\right] \\
+ & \frac{1}{2}\left[b_{0}-c_{0}+\left(b_{1}-c_{1}-\delta\right)\left(\frac{p-c_{1}-\delta}{c_{2}}\right)-\frac{\left(b_{2}+c_{2}\right)}{2}\left(\frac{p-c_{1}-\delta}{c_{2}}\right)^{2}\right]
\end{aligned}
$$

Taking the derivative of this expression with respect to $p$, setting equal to zero, and multiplying through by $2 c_{2}$ gives

$$
b_{1}-c_{1}-\delta-\left(1+\frac{b_{2}}{c_{2}}\right)\left(p-c_{1}-\delta\right)=0 \text {. }
$$

And solving for $p$ gives an expression for the optimal trigger price,

$$
p^{*}=\left(1+\frac{b_{2}}{c_{2}}\right)^{-1} b_{1}+\left[1-\left(1+\frac{b_{2}}{c_{2}}\right)^{-1}\right]\left(c_{1}+\delta\right) .
$$

In the general case, the optimal trigger price will be a weighted average between the marginal benefits and the marginal cost in the high cost case, where the relative weight of the terms depends on the relative slopes of marginal costs and benefits. In general, the optimal trigger price will be higher than the marginal benefits (the optimal price for a pure price instrument. However, in the special case of a stock pollutant, such as greenhouse gases, it has been suggested (Pizer, 1999) that $b_{2}$ can be treated as approximately zero (constant marginal benefits). In this special case, the optimal trigger price reduces to simply $p^{*}=b_{1}$. The optimal trigger price for a hybrid instrument for a stock pollutant is the same as the optimal tax, equal to the marginal benefits. Because the 
optimal trigger price does not depend on the choice of emissions limit $q^{*}$, this result holds for any choice of emissions limit $q$ for the hybrid.

Note that this result for the optimal trigger price is not a new result. This is simply the ceiling price for the hybrid policy of Roberts and Spence (1976). Roberts and Spence showed that for a general pollution externality, the optimal instrument was a hybrid with an emissions cap, a ceiling price, and a floor price (or subsidy), which is preferred over a pure cap or a pure tax. The intuition is that the step function created by policy approximates the marginal benefit function. Roberts and Spence noted that for the special case of constant marginal benefits, their optimal hybrid converges to a pure price instrument equal to the marginal benefits.

\section{b. Expected Net benefits of Hybrid Instrument}

For the remainder of this paper, we will restrict our consideration to pure stock pollutants (such as long-lived greenhouse gases) for which we will assume that the marginal benefits in any single period are essentially constant; i.e., we assume $b_{2}$ equals zero. As the above discussion has shown, for this case the optimal trigger price is equal to the marginal benefits at the expected level of abatement $\left(q^{*}\right)$. We can now relax the assumption of a discrete distribution of the cost uncertainty $\theta$, and allow any distribution such that $E\{\theta\}=0$ and $\operatorname{VAR}(\theta)=\sigma^{2}$.

For any distribution of $\theta$ around zero, the trigger price will be activated with probability $\pi$, and the emissions limit will be binding with probability $1-\pi$. The expected net benefits of a hybrid instrument under these conditions is: 


$$
\begin{aligned}
& E\left\{N B_{s v}\right\}=(1-\pi) E_{\theta}\left[b_{0}-c_{0}+\left(b_{1}-c_{1}-\theta\right)\left(q^{*}-q^{*}\right)-\frac{\left(b_{2}+c_{2}\right)}{2}\left(q^{*}-q^{*}\right)^{2}\right] \\
& +\pi E_{\theta}\left[b_{0}-c_{0}+\left(b_{1}-c_{1}-\delta\right)\left(q^{*}+\frac{\theta}{c_{2}}-q^{*}\right)-\frac{\left(b_{2}+c_{2}\right)}{2}\left(q^{*}+\frac{\theta}{c_{2}}-q^{*}\right)^{2}\right] \\
& =E_{\theta}\left\{b_{0}-c_{0}+\pi \frac{\left(b_{1} \theta-c_{1} \theta\right)}{c_{2}}+\pi \frac{\left(c_{2}-b_{2}\right) \theta^{2}}{2 c_{2}^{2}}\right\}
\end{aligned}
$$

(14) $=b_{0}-c_{0}+\pi \frac{\left(c_{2}-b_{2}\right) \sigma^{2}}{2 c_{2}^{2}}$.

Thus the additional net benefit of a hybrid relative to a quantity instrument is:

$$
\Delta_{s v-q}=\frac{\pi\left(c_{2}-b_{2}\right) \sigma^{2}}{2 c_{2}^{2}}=\pi \Delta_{p-q} .
$$

For example, if the distribution for $\theta$ is symmetric, then $\pi=1-\pi=0.5$ and the advantage of the safety valve relative to a quantity instrument is exactly half the advantage of the price instrument over the quantity instrument, $\Delta_{s v-q}=\frac{\Delta_{p-q}}{2}$.

\section{c. Safety Valve Vs. General Indexed Quantity}

Newell and Pizer (2006) extended the Weitzman model to represent intensity targets. Intensity targets, where the emissions limit is determined from the GDP which is uncertain and a desired emissions intensity ratio, fall under the general category of indexed quantity instruments. The most general form of indexed quantities, which Newell and Pizer refer to as a General Indexed Quantity (GIQ) chooses emissions $q$ as a linear function of another random variable $x$ as

$$
q(x)=a+r x
$$


Where $a$ and $r$ are policy design variables, and $E\{x\}=\bar{x}, \operatorname{var}(x)=\sigma_{x}^{2}$, and $\operatorname{cov}(x, \theta)=\sigma_{c x}$. Newell and Pizer show that the optimal choice of an indexed quantity is

$$
q_{G I Q}^{*}(x)=q^{*}+r^{* *}(x-\bar{x})
$$

where $r^{* *}=\left(\sigma_{c x} / \sigma_{x}^{2}\right) /\left(b_{2}+c_{2}\right)$, and the resulting expected net benefits are

$$
E\left\{N B_{G I Q}\right\}=b_{0}-c_{0}+\frac{\sigma_{c}^{2}}{2\left(c_{2}+b_{2}\right)} \rho_{c x}^{2}
$$

We are interested here in when a hybrid instrument is preferred over an intensity target or vice versa. When the distribution of $\theta$ is symmetric, the expected net benefits of the hybrid is as given in equation (14). Comparing with (19), the indexed quantity will be preferred when

$$
\frac{\sigma_{c}^{2}}{2\left(c_{2}+b_{2}\right)} \rho_{c x}^{2}>\frac{\left(c_{2}-b_{2}\right) \sigma_{c}^{2}}{2 c_{2}^{2}} \pi
$$

Rearranging to solve for $\rho$, the intensity target is preferred when

$$
\rho_{c x}^{2}>\frac{\left(c_{2}-b_{2}\right)\left(c_{2}+b_{2}\right)}{c_{2}^{2}} \pi
$$

For the case of a stock pollutant, where $b_{2} \cong 0$, this simplifies to

$$
\rho_{c x}>\sqrt{\pi}
$$

For example, if the distribution is symmetric and the probability of activating the trigger price is $1 / 2$, then the intensity target would be preferred when the correlation $\rho_{c x}$

exceeds $1 / \sqrt{2} \cong 0.71$. As one should expect, the indexed quantity instrument is preferred when the correlation between emissions and the index quantity (e.g., GDP) is high enough. If the correlation were perfect, $\rho=1$, then the indexed quantity is preferable. If 
there was no correlation, $\rho=0$, the hybrid would be preferred. The correlation for which one should be indifferent between the two instruments is the square root of the probability of the trigger price activating under the hybrid.

\section{d. Safety Valve vs. Indexed Quantity}

The most common form of intensity target under consideration in climate policy discussions would not take the most general form of the indexed quantity as described above. Newell and Pizer point out that a GDP intensity target would set the variable $a$ in equation (19) to zero. They refer to this instrument as an Indexed Quantity (IQ), in contrast to the GIQ above, and its optimal form is:

$$
q_{I Q}^{*}(x)=r^{*} x
$$

Where $r^{*}=\left(1+v_{x}^{2}\right)^{-1}\left(\left(q^{*} / \bar{x}\right)+v_{x}^{2} r^{* *}\right)$ and $v_{x}=\sigma_{x} / \bar{x}$. Newell and Pizer show that if $\rho_{c x} \neq 0$, the expected net benefits for the indexed quantity is

$$
E\left\{N B_{I Q}\right\}=b_{0}-c_{0}+\frac{\sigma_{c}^{2}}{2\left(c_{2}+b_{2}\right)} \rho_{c x}^{2}\left(1-\frac{1}{1+v_{x}^{2}}\left(1-\frac{v_{x}}{\rho_{c x} v_{q^{*}}}\right)^{2}\right)
$$

where $v_{q^{*}}=\left(\sigma_{c} /\left(b_{2}+c_{2}\right)\right) / q^{*}$.

Comparing the net benefits for the IQ (equation 23) with the net benefits for the hybrid (equation 14), the critical correlation where the relative net benefits of IQ are positive is a quadratic function of the ratio of the coefficient of variation (the standard deviation relative to the mean) of the indexed quantity (GDP) to the coefficient of variation of the emissions, $v_{x} / v_{q}$. We plot this relationship for a wide range of possible values of $v_{x}$ and $v_{q}$ for a distribution of $\theta$ where $\pi=0.5$ (Figure 1). If this ratio is less 
than 0.25 or greater than 1.8 , the hybrid instrument is always preferred. Thus the intensity target is most useful in cases where the magnitude of the uncertainties in cost and the index are roughly comparable, as also suggested by Newell and Pizer. For ratios between 0.25 and 1.8 , the minimum correlation for which one would be indifferent between the two instruments follows the curve in Figure 1. Note that a ratio of $v_{x} / v_{q}=0.71$ (corresponding to $v_{x} /\left(v_{q} \rho_{c x}\right)=1$ ), the indexed quantity has the same indifference correlation as the general indexed quantity, $1 / \sqrt{2}$.

\section{Numerical Example}

We illustrate the above analytical expressions by performing an uncertainty analysis on a computable general equilibrium model of the U.S. economy, and show the conditions under which an intensity target will be preferred to a safety valve or vice versa. We first briefly describe the model and the uncertainty analysis, then give the results from the model and compare to the analytical model from the previous section.

\section{a. Model Description}

We test the predictions of the preferred instrument using a static CGE model of the U.S. The model treats households as an aggregate representative agent with constant elasticity of substitution (CES) preferences. Industries are consolidated into the 11 sectoral groupings shown in Table 3, and are treated as representative firms with nested CES production technology. For this purpose we adapt Bovenberg and Goulder's (1996) KLEM production technology and parameterization, as shown in Figure 2. Additional details are given in the appendix. 
The model's algebraic structure is numerically calibrated using U.S. data on interindustry economic flows, primary factor demands, commodity uses and emissions in the year 2004. We simulate prices, economic quantities, and emissions of $\mathrm{CO}_{2}$ in the year 2015 by scaling both the economy's aggregate factor endowment and the coefficients on energy within industries' cost functions and the representative agent's expenditure function. The probability distributions of these scaling factors, when propagated through the model, give rise to probability distributions for the future value of baseline national income, energy use and emissions.

The parameters which govern the malleability of production are the elasticities of substitution between composites of primary factors $(K L)$ and intermediate inputs $(E M)$, which we denote $\sigma_{K L E M}$; between inputs of capital $(K)$ and labor $(L)$, denoted by $\sigma_{K L}$; between energy $(E)$ and materials $(M)$, indicated by $\sigma_{E M}$; and among different intermediate energy and material commodities ( $e$ and $m$ ), denoted by $\sigma_{E}$ and $\sigma_{M}$, respectively. In natural resource-dependent sectors (e.g., production of primary fuels such as coal) the resource is modeled as a fixed factor which enters at the top of the production hierarchy, governed by the elasticity $\sigma_{R}$. The electric power sector encompasses two nested production structures, one for primary electricity generated from fixed factors (e.g., nuclear, hydro and wind) which exhibits features of resource-dependent sectors, and another representing fossil fuel generation which exhibits features of non-resource sectors. Probability distributions for these seven parameters, when propagated through the model, generate probability distributions for the changes in income and emissions from their baseline levels in response to climate policy. 


\section{b. Parametric Uncertainty}

For this analysis of near-term carbon abatement policies, we consider uncertainty in three categories of parameters: the GDP growth rate of the economy between 2005 and 2015, the rate of autonomous energy efficiency improvement (AEEI), and the elasticities of substitution in the production functions. We briefly summarize here the probability distributions for the uncertainty parameters, and a detailed description can be found in (Webster et al., 2007).

Annual GDP growth rates are modeled as a random walk with drift (Stock and Watson, 1988; Schwartz and Smith, 2000). The volatility is estimated from GDP time series data for the U.S. economy from 1970-2000 (BEA, 2007). For projecting from 2005 to 2015, instead of the historical mean growth rate, we use the reference EIA forecast (EIA, 2007) growth rate of 3\% per annum. Our estimated volatility results in a distribution of future growth rates with $+/$ - one standard deviation almost identical to the EIA high and low growth cases.

The AEEI parameter has a reference (mean) value of $1.0 \%$ p.a., consistent with many other energy economic models (Azar and Dowlatabadi, 1999). The uncertainty in AEEI is assumed to be normal with a standard deviation of $0.4 \%$ based on several analyses (Scott et al., 1999; Webster et al., 2002).

The uncertainties in the elasticities of substitution are based on literature survey of econometric estimates with published standard errors. The details of this survey and the synthesis of the standard errors into a probability distribution for each elasticity are documented fully in Webster et al (2007). The empirical probability distributions for each of these parameters are summarized in Table 1, along with representative statistics. 


\section{c. Results of CGE Model}

We perform Monte Carlo simulation on the CGE model, drawing 1000 random samples of parameter values. In addition to the reference (no policy) case, we impose four types of policy constraints: an emissions cap, a carbon tax, a safety valve, and an intensity target. The stringency of the emissions cap is defined as the expected $\mathrm{CO}_{2}$ abatement under the McCain-Lieberman Senate Bill (Paltsev et al., 2007) of $2100 \mathrm{Mt}$ $\mathrm{CO}_{2}$, leaving U.S. emissions in 2015 at $5000 \mathrm{Mt} \mathrm{CO}_{2}$, and at a marginal cost of \$23/ton $\mathrm{CO}_{2}$. We define all other policy instruments such that they will be equivalent in the mean case; the carbon tax is $\$ 23 /$ ton $\mathrm{CO}_{2}$, the trigger price of the safety valve is $\$ 23 /$ ton $\mathrm{CO}_{2}$, and the intensity target requires an emissions/GDP ratio to be the same as that which results under the quantity instrument in the mean case. Finally, a critical assumption in the results shown here is that the marginal benefit of $\mathrm{CO}_{2}$ abatement in 2015 is assumed to be $\$ 23 /$ ton $\mathrm{CO}_{2}$; i.e., we assume that the imposed policies are all optimal in the nouncertainty case.

The mean and standard deviations for key results are given in Table 2. The expected abatement of $\mathrm{CO}_{2}$ is the same for all instruments except the safety valve, which abates less than the others. The safety valve also has greater uncertainty in the abatement than either the tax or intensity targets, but less than the emissions cap. The uncertainty in marginal costs of abatement are greatest for the cap and no uncertainty for the tax (by definition), with the safety valve having the next smallest uncertainty. Expected net benefits (calculated assuming a marginal benefit of abatement of $\$ 23 /$ ton) are, consistent with theory, greatest for the tax and least for the cap. The safety valve and the intensity target have similar expected net benefits, but the intensity target is preferred. The 
correlation between GDP and emissions in the no policy case is calculated as 0.87 , so this is consistent with the expressions in Section 3.

To further test the consistency between the CGE and analytical models, we construct an experiment to artificially vary the correlation between GDP and emissions in the Monte Carlo simulation. We cannot directly impose a correlation, since the emissions are an endogenous function of GDP growth and other factors. Instead, we artificially increase or decrease the variance of the GDP growth rate uncertainty, while holding constant the variance of AEEI and the elasticities of substitution. This procedure causes the correlation between GDP and emissions to vary across different sets of random samples.

Six different sets of random samples are drawn, with correlation between GDP and emissions ranging from 0.65 to 0.93 . The value of correlation for which one would be indifferent between the intensity and safety valve instruments is 0.86 (Figure 3). In contrast, the coefficients of variation for GDP and emissions from the CGE model are 0.79 and 0.84 , respectively, giving a ratio $v_{x} / v_{q}$ equal to 0.94 . The relationship plotted in Figure 1 predicts an indifference correlation value of 0.74 for these parameter values.

The divergence in the indifference point correlation between the CGE model and the analytical model results from the non-linearity of the marginal abatement cost from the model. Our analytical model, like Weitzman's model, assumes linear marginal costs, whereas the marginal costs predicted by the CGE model are approximately cubic (Figure 4). A non-linear marginal cost curve favors a policy in which the expected abatement is lower than the optimal abatement under certainty (the reference cap), because beyond the point of optimal abatement marginal costs are steeply increasing. As an illustration, we 
use the average marginal abatement cost curve from 1000 runs of the CGE model (Figure 5), and calculate the loss in net benefits from 1000mmt more or less than optimal abatement; the net benefit loss in area $\mathrm{B}, \$ 14,797 \mathrm{~B}$, is more than twice that of area $\mathrm{A}$, $\$ 8,873 \mathrm{~B}$. A safety valve will always result in abatement less than or equal to the reference cap, while an intensity target may require abatement either above or below the reference cap. Non-linear marginal costs thus induce a bias in favor of the safety valve, as the instrument operates solely in the region where marginal costs are favorable. We should thus expect that the CGE model with cubic marginal costs will predict a higher indifference point correlation than the analytical model, which is what we see here.

To test this hypothesis, one would ideally perform an identical experiment except with linear marginal abatement costs. However, there is no simple way to modify a CGE model to induce global linearity. As an approximation, we impose a less stringent emissions target $(6200 \mathrm{mmt})$ in the CGE model, such that the relevant portion of the marginal cost curve is nearly linear. We repeat the above Monte Carlo experiments, for several different assumed variances for the GDP uncertainty, and calculate the expected net benefits under the hybrid and indexed instruments (Figure 3). Under the less stringent target, the critical value of correlation for which the intensity target becomes preferred over the safety valve is 0.74 , as predicted by the analytical model.

The preferred policy instrument is thus dependent on the slope of the marginal cost curve over the span of potential abatement. Because the actual economy is unlikely to have strictly linear marginal abatement costs, the range of conditions in which the intensity target is preferable to the safety valve, especially given a reasonably stringent emissions target, is probably quite narrow. 


\section{Discussion}

Given the uncertainty in economic growth and the cost of abating $\mathrm{CO}_{2}$ emissions, an emissions cap chosen today for some future year has the potential for extremely high welfare loss. The preferable economic instrument for a stock pollutant, a carbon tax, seems politically infeasible at least in the U.S. and perhaps in other countries as well. This leads to interest in either a safety valve or an intensity target as a regulatory instrument that has less uncertainty in the cost of abatement and welfare losses.

Our analysis has shown that, if both instruments are optimally designed, a high level of correlation (at least 0.7 and often higher) between the cost uncertainty and the index uncertainty are required to justify the choice of an intensity target as a regulatory instrument over a safety valve. The design details of the actual policy are critical to the choice between instruments. For example, a hybrid with a trigger price much lower than the marginal benefits will be much less efficient, and an intensity target may be superior.

The analysis presented here focuses exclusively on a single period of relatively few years. For longer time frames divided into multiple periods, an additional question is how banking and borrowing of emissions permits would perform relative to either a safety valve or an intensity target. Finally, there is a question about how a single period analysis that allows emissions to be higher or lower in response to uncertainty can be made consistent with a long-term target, such as concentration stabilization, where less abatement in one period must be compensated by abatement in another period. 


\section{Acknowledgements}

This work was supported by a grant from the Doris Duke Charitable Foundation (\#). The authors are grateful for helpful comments from Mustafa Babiker, Denny Ellerman, Karen Fisher-Vanden, Gib Metcalf, and Marcus Sarofim. 


\section{References}

Armington, P.S. (1969). A Theory of Demand for Products Distinguished by Place of Production (Une théorie de la demande de produits différenciés d'après leur origine) (Una teoría de la demanda de productos distinguiéndolos según el lugar de producción). Staff Papers - International Monetary Fund 16 (1) (Mar., 1969) pp. $159-178$.

Azar, C. and H. Dowlatabadi (1999). "A Review of Technical Change in Assessment of Climate Policy.” Annual Review of Energy and the Environment, 24: 513-44.

Bovenberg, A.L. and L.H. Goulder (1996). Costs of environmentally motivated taxes in the Presence of other taxes: general equilibrium analyses, American Economic Review 86: 985-1006.

Brooke, A., D. Kendrick, A. Meeraus, and R. Raman (1998). GAMS: A User's Guide, Washington DC: GAMS Development Corp.

Bureau of Economic Analysis (2007). "Current-dollar and 'real' GDP,” National Economic Accounts. http://www.bea.gov/national/index.htm.

Dirkse, S.P. and M.C. Ferris (1995). The PATH Solver: A Non-Monotone Stabilization Scheme for Mixed Complementarity Problems, Optimization Methods and Software 5: 123-156.

Ellerman, A.D., \& B. Buchner (December 2006). “Over-Allocation or Abatement? A Preliminary Analysis of the EU Emissions Trading Scheme Based on the 2005 Emissions Data," Report No. 141, Joint Program on the Science and Policy of Global Change, MIT, Cambridge, MA. Or see http://web.mit.edu/globalchange/www/MITJPSPGC_Rpt141.pdf. 
Ellerman, A. D. and I. Sue Wing (2003). "Absolute vs. Intensity-Based Emission Caps," Climatic Policy 3 (Supplement 2): S7-S20.

Energy Information Agency (2007). Annual Energy Outlook 2007 with Projections to 2030. http://www.eia.doe.gov/oiaf/aeo/index.html.

Harrison, G.W., D. Tarr and T.F. Rutherford (1997). Quantifying the Uruguay Round, Economic Journal 107: 1405-1430.

Jacoby, H.D. \& A.D. Ellerman (2004). “The Safety Valve and Climate Policy,” Energy Policy 32 (4): 481-491.

Mathiesen, L. (1985a). Computational Experience in Solving Equilibrium Models by a Sequence of Linear Complementarity Problems, Operations Research 33: 12251250.

Mathiesen, L. (1985b). Computation of Economic Equilibria by a Sequence of Linear Complementarity Problems, Mathematical Programming Study 23: 144-162.

Newell, R. G. and W. A. Pizer (2006). "Indexed Regulation," Resources for the Future Discussion Paper DP 06-32. http://www.rff.org/Documents/RFF-DP-06-32.pdf.

Paltsev, S., J. Reilly, H. Jacoby, A. Gurgel, G. Metcalf, A. Sokolov \& J. Holak (April 2007). “Assessment of U.S. Cap-and-Trade Proposals," Report No. 146, Joint Program on the Science and Policy of Global Change, MIT, Cambridge, MA. Or see http://web.mit.edu/globalchange/www/MITJPSPGC_Rpt146.pdf.

Pizer, W. A. (2002). “Combining price and quantity controls to mitigate global climate change," Journal of Public Economics 85: 409-434. 
Pizer, W. A. (1999). "Optimal Choice of Policy Instrument and Stringency under Uncertainty: The Case of Climate Change," Resource and Energy Economics 21: 255-287.

Pizer, W. A. (2005). “Climate Policy Design under Uncertainty,” Resources for the Future Discussion Paper DP 05-44. http://www.rff.org/Documents/RFF-DP-0544.pdf.

Quirion, P. (2005). “Does Uncertainty Justify Intensity Emissions Caps?” Resource and Energy Economics 27: 343-353.

Roberts M. J. and M. Spence (1976). "Effluent Charges and Licenses under Uncertainty." Journal of Public Economics 5: 193-208.

Rutherford, T.F. (1999). Applied General Equilibrium Modeling with MPSGE as a GAMS Subsystem: An Overview of the Modeling Framework and Syntax, Computational Economics 14: 1-46.

Scarf, H. (1973). The Computation of Economic Equilibria, New Haven: Yale University Press.

Schwartz, E. and J. E. Smith (2000). "Short-Term Variations and Long-Term Dynamics in Commodity Prices," Management Science 46 (7): 893-911.

Scott, M. J., R. D. Sands, J. Edmonds, A. M. Liebetrau, and D. W. Engel (1999). "Uncertainty in Integrated Assessment Models: Modeling with MiniCAM 1.0." Energy Policy 27 (14): 597.

Stock, J. H. and M. W. Watson (1988). "Variable Trends in Economic Time Series," The Journal of Economic Perspectives 2 (3): 147-174. 
Stolberg, S. G. (2007). “At Group of 8 Meeting, Bush Rebuffs Germany on Cutting Emissions.” New York Times, June 7, 2007. file://C:/Documents\%20and\%20Settings/mort/My\%20Documents/Research/ENT ICE/LISA/NYTimes\%20article\%20-\%20EU\%20target.htm.

Sue Wing, I., A.D. Ellerman \& J. Song (2006). “Absolute vs. Intensity Limits for $\mathrm{CO}_{2}$ Emission Control: Performance under Uncertainty" Report No. 130, Joint Program on the Science and Policy of Global Change, MIT, Cambridge, MA. Or see http://web.mit.edu/globalchange/www/MITJPSPGC_Rpt130.pdf.

Sue Wing, I. (2004). Computable General Equilibrium Models and Their Use in Economy-Wide Policy Analysis: Everything You Ever Wanted to Know (But Were Afraid to Ask), MIT Joint Program on the Science and Policy of Global Change Technical Note No. 6, Cambridge MA.

Sue Wing, I. (2006). The Synthesis of Bottom-Up and Top-Down Approaches to Climate Policy Modeling: Electric Power Technologies and the Cost of Limiting U.S. $\mathrm{CO}_{2}$ Emissions, Energy Policy 34: 3847-3869.

Webster, M.D., M. Babiker, M. Mayer, J.M. Reilly, J. Harnisch, M.C. Sarofim, and C. Wang (2002). "Uncertainty in Emissions Projections for Climate Models." Atmospheric Environment 36 (22) 3659-3670.

Webster, M. D., I. Sue Wing , L. Jakobovits, and T. Felgenhauer (2007). "Uncertainty in costs and abatement from near-term carbon reduction policies in the U.S." (working paper).

Weitzman, M. L. (1974). “Prices vs. Quantities,” The Review of Economic Studies 41 (4): 477-491. 
Weitzman, M. L. (1978). “Optimal rewards for Economic Regulation,” American Economic Review 68 (4): 683-691. 
Table 1: Uncertain Parameter Distributions for Monte Carlo Simulations

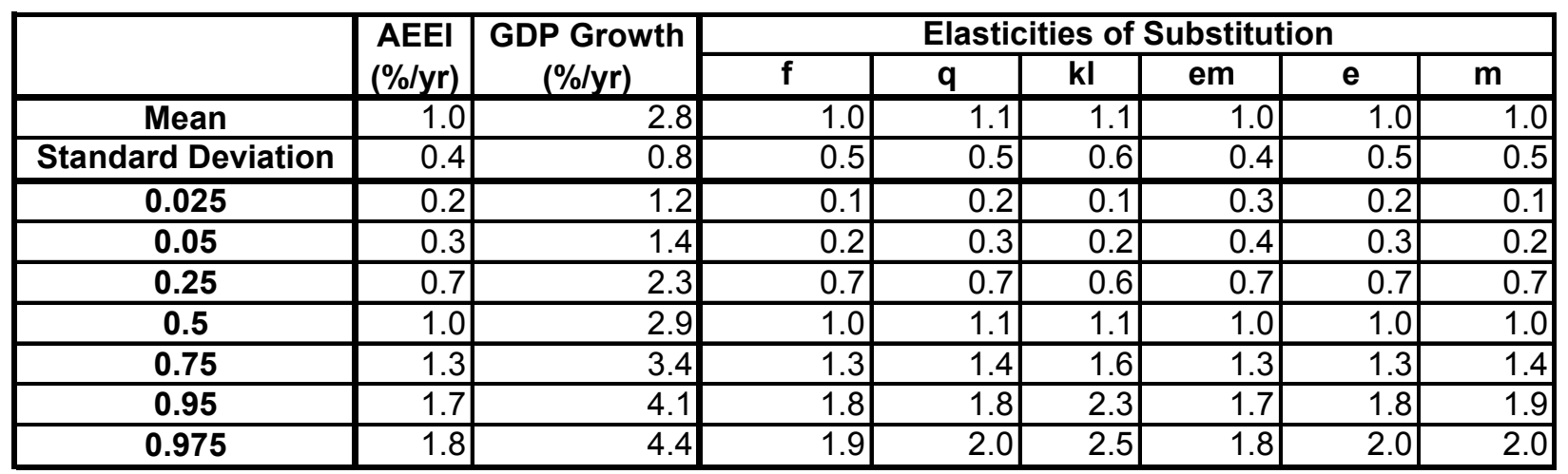


Table 2: Results of Monte Carlo Simulations

\begin{tabular}{|l|r|r|r|r|r|r|}
\hline & \multicolumn{2}{|c|}{ Abatement (Mt CO2) } & \multicolumn{2}{c|}{ Carbon Price (\$/ton CO2) } & \multicolumn{2}{c|}{ Net Benefits (\$M) } \\
\hline & \multicolumn{1}{|c|}{ Mean } & St. Dev. & Mean & \multicolumn{1}{c|}{ St. Dev. } & \multicolumn{1}{c|}{ Mean } & \multicolumn{1}{c|}{ St. Dev. } \\
\hline Cap & 2052 & 593 & 23.0 & 10.8 & 23231 & 5118 \\
\hline Tax & 2099 & 322 & 22.7 & 0.0 & 25341 & 3738 \\
\hline Safety Valve & 1887 & 453 & 18.7 & 5.1 & 24273 & 4451 \\
\hline Intensity & 2108 & 316 & 23.8 & 7.7 & 24363 & 4423 \\
\hline
\end{tabular}




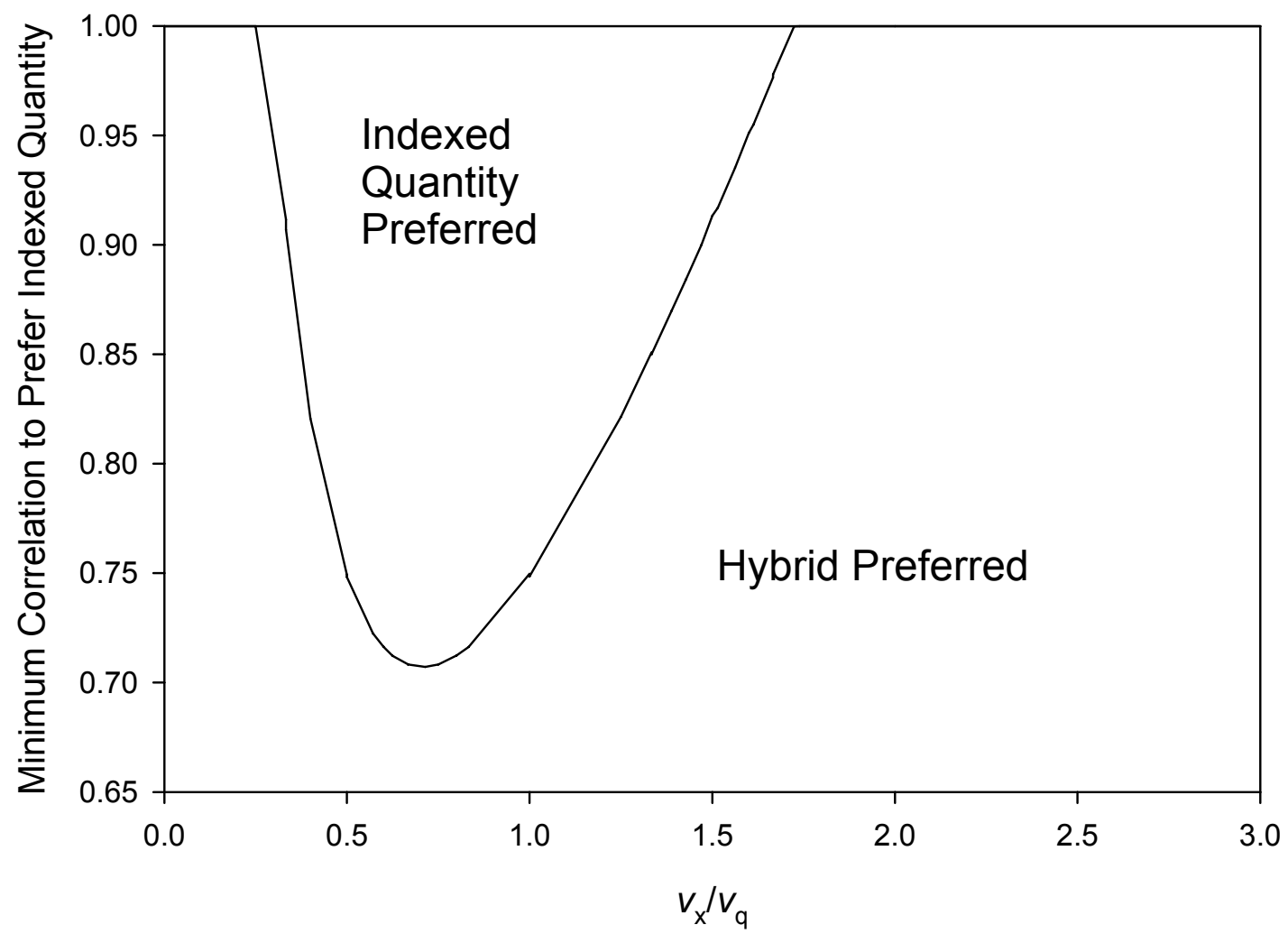

Figure 1: Critical correlation between index and cost uncertainty for indexed quantity instrument to be preferred over hybrid, as a function of the ratio of the coefficients of variation for indexed quantity $x$ and emissions $q$. 


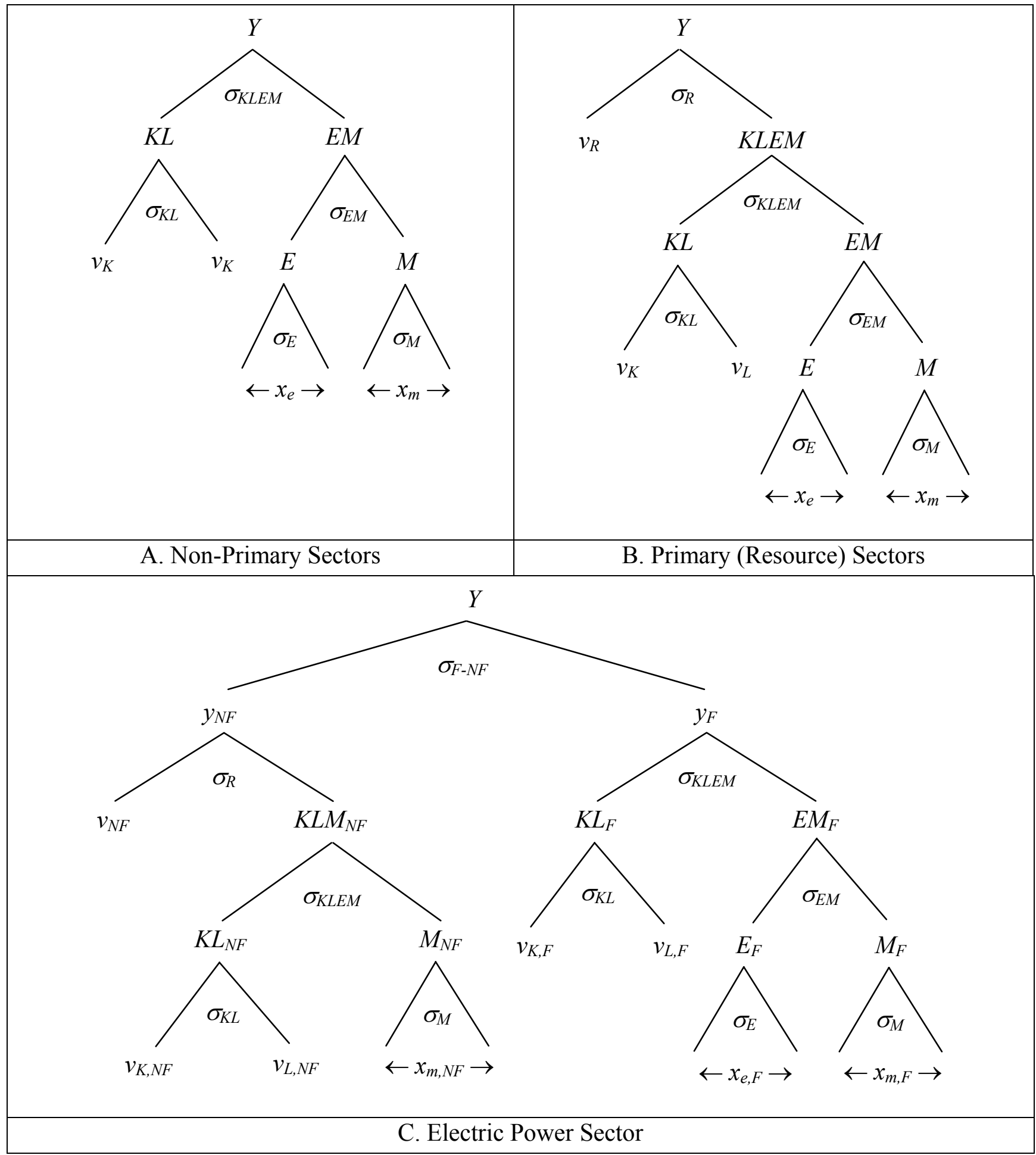

Figure 2. The Structure of Production in the CGE Model. 


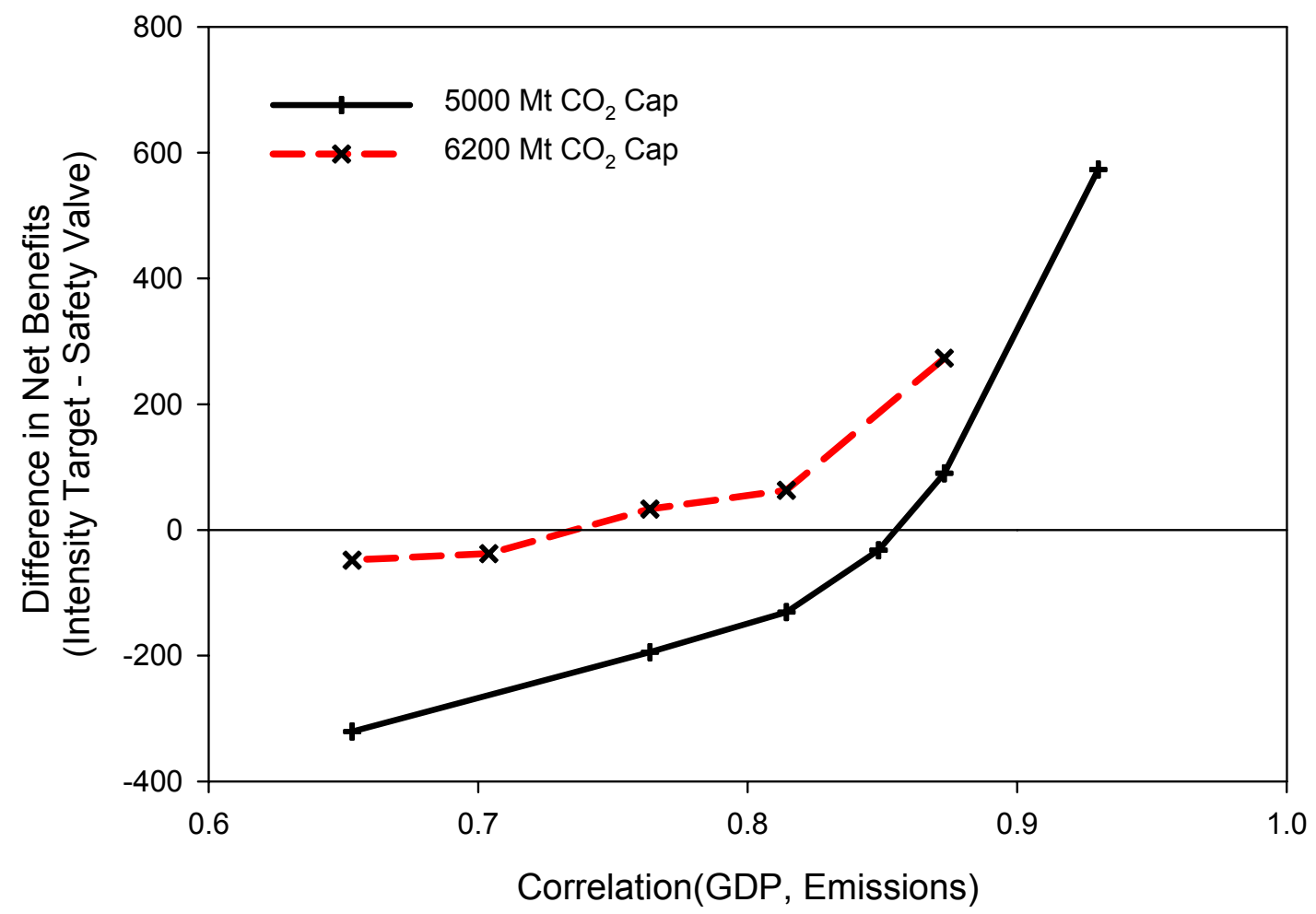

Figure 3: Relative advantage of intensity target to safety valve as a function of correlation between GDP and baseline emissions. For an emissions target of $5000 \mathrm{mmt}$, a higher correlation (at least 0.86 ) is necessary for the intensity target to be the preferred instrument. For a less stringent target $(6200 \mathrm{mmt})$, for which the relevant portion of the MAC curve is nearly linear, the indifference point between the intensity target and safety valve occurs at 0.74 , as was predicted by the analytical model. 


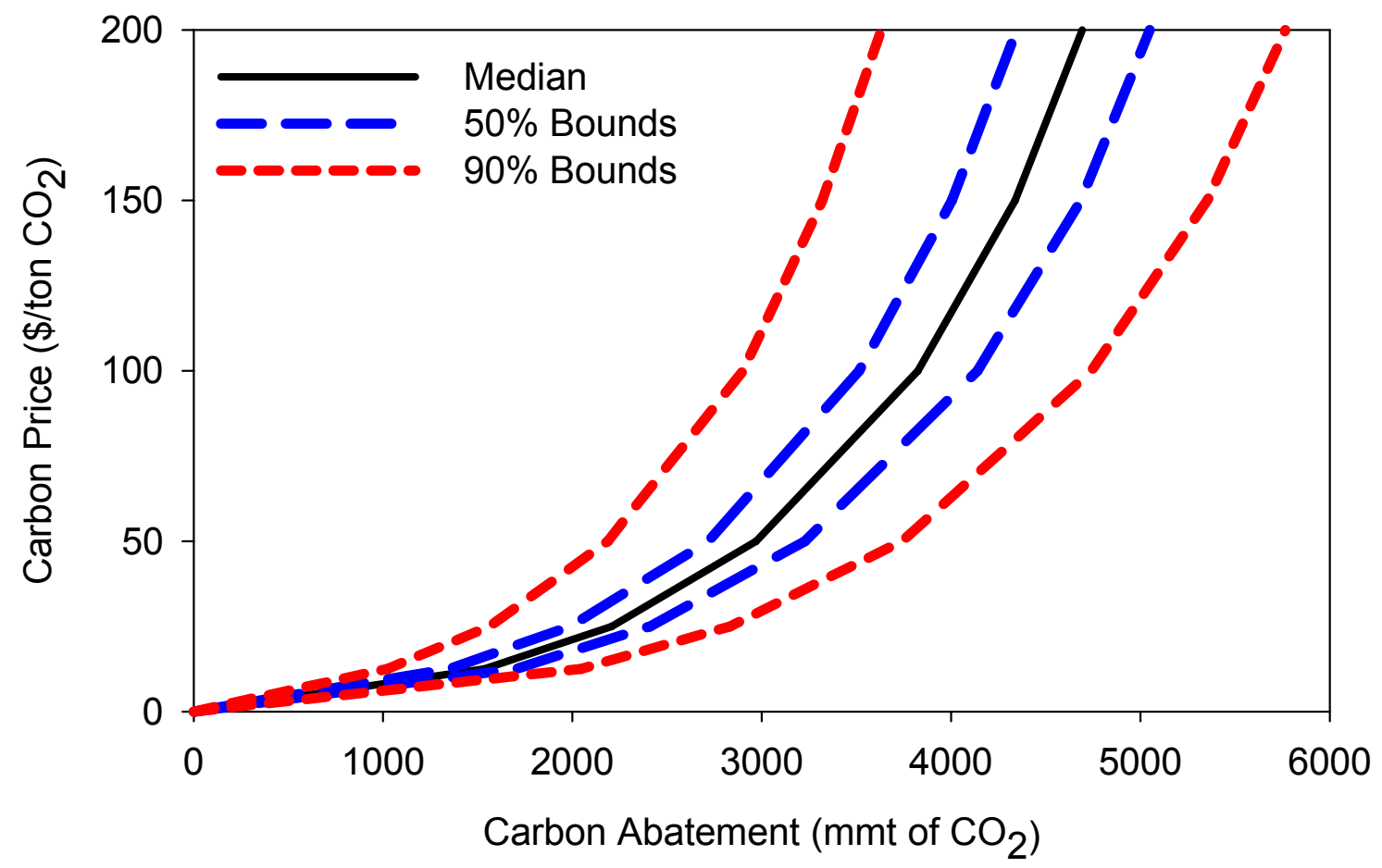

Figure 4: Uncertainty in marginal abatement costs in computable general equilibrium model as a result of uncertainty in GDP growth, AEEI, and elasticities of substitution. 


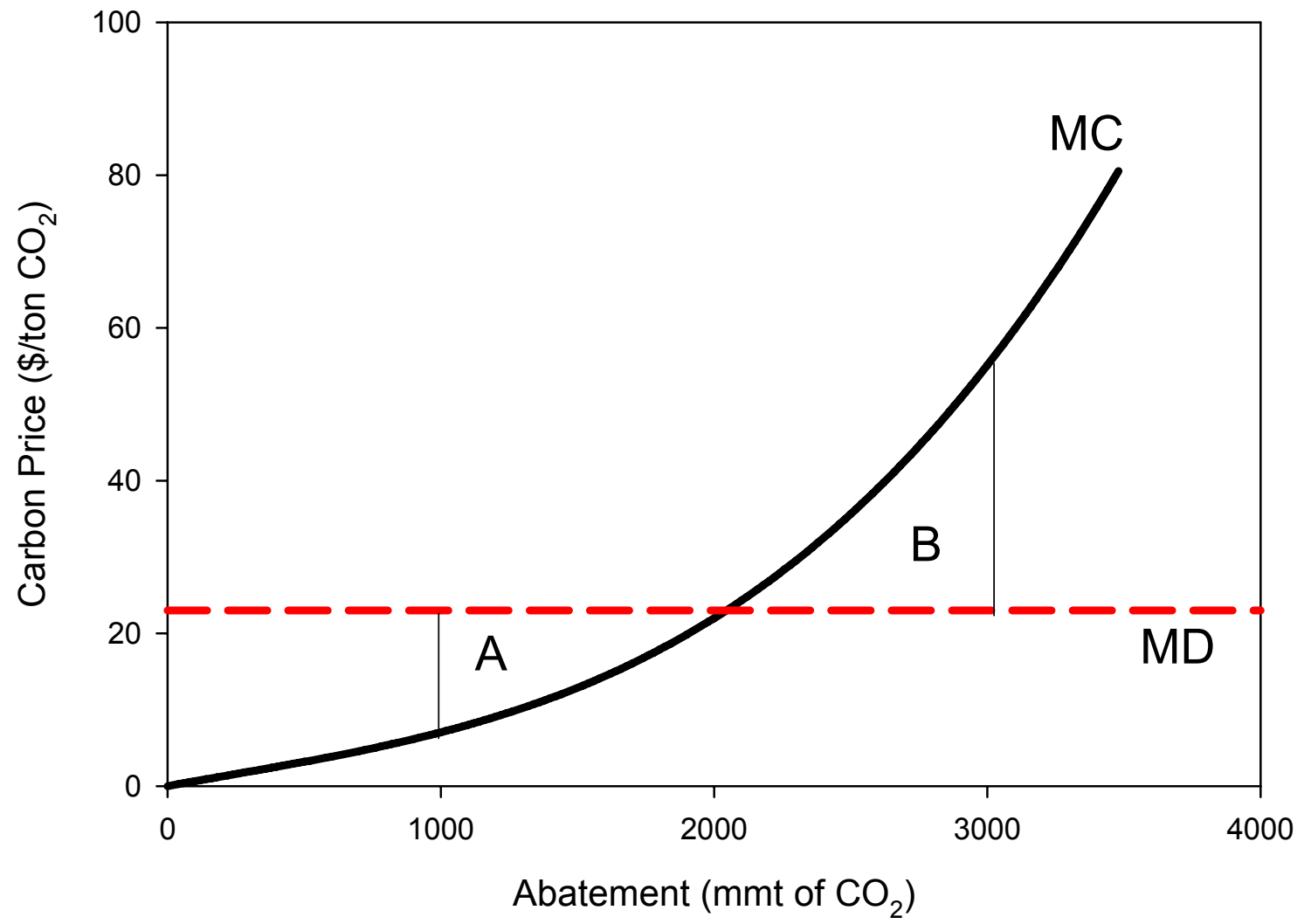

Figure 5: Loss in expected net benefits in CGE model from abatement 1000mmt less than optimal and 1000mmt more than optimal. Area A represents the net benefits lost from abating too little $(\$ 8,873 \mathrm{~B})$, which is substantially smaller than area $\mathrm{B}$, the net benefits lost from abating too much $(\$ 14,797 \mathrm{~B})$. 


\section{Appendix: Description of the CGE Model}

The simulations in the paper are constructed using a simple static CGE simulation of the U.S. economy. The model treats households as a representative agent, aggregates the firms in the economy into 11 industry sectors, and solves for a static equilibrium in the year 2015 .

\section{A.1 Model Structure}

The model is a simplified version of that developed by Sue Wing (2006). It represents the U.S. in the small open economy format of Harrison et al (1997). Imports and exports are linked by a balance-of-payments constraint, commodity inputs to production or final uses are modeled as Armington (1969) CES composites of imported and domestically-produced varieties, and industries' production for export and the domestic market are modeled according to constant elasticity of transformation (CET) functions of their output.

Commodities (indexed by $i$ ) are of two types, energy goods (coal, oil, natural gas and electricity, denoted $e \subset i$ ) and non-energy goods (denoted $m \subset i$ ). Each good is produced by a single industry (indexed by $j$ ), which is modeled as a representative firm that generates output $(Y)$ from inputs of primary factors $(v)$ and intermediate uses of Armington commodities $(x)$.

Households are modeled as a representative agent who is endowed with three factors of production, labor $(L)$, capital $(K)$ and industry-specific natural resources $(R)$, indexed by $f=\{L, K, R\}$. The supply of capital is assumed to be perfectly inelastic. The endowments of the different natural resources increase with the prices of domestic output 
in the industries to which these resources correspond, according to sector-specific supply elasticities, $\eta_{R}$. Income from the agent's rental of these factors to the firms finances her consumption of commodities, consumption of a government good, and savings.

The representative agent's preferences are modeled according to a CES expenditure function. The agent is assumed to exhibit constant marginal propensity to save, so that savings make up a constant fraction of aggregate expenditure. The government sector is modeled as a passive entity which demands commodities and transforms them into a government good, which in turn serves as an input to both consumption and investment. Aggregate investment and government output are produced according to CES transformation functions of the goods produced by the industries in the economy. The demand for investment goods is specified according to a balanced growth path rule.

Production in industries is represented by the multi-level CES cost functions shown schematically in Figure 2, which are adaptations of Bovenberg and Goulder's (1996) structure. Each node of the tree in the diagram represents the output of an individual CES function, and the branches denote its inputs. Thus, in the non-resource based production sectors shown in panel A, output $\left(Y_{j}\right)$ is a CES function of a composite of labor and capital inputs $\left(K L_{j}\right)$ and a composite of energy and material inputs $\left(E M_{j}\right) . K L_{j}$ represents the value added by primary factors' contribution to production, and is a CES function of inputs of labor, $v_{L j}$, and capital, $v_{K j}$. $E M_{j}$ represents the value of intermediate inputs' contribution to production, and is a CES function of two further composites: $E_{j}$, which is itself a CES function of energy inputs, $x_{e j}$, and $M_{j}$, which is a CES function of non-energy material inputs, $x_{m j}$. 
The production structure of resource-based industries is shown in panel B. In line with its importance to production in these industries, the natural resource is modeled as a sector-specific fixed factor whose input enters at the top level of the hierarchical production function. Output is thus a CES function of the resource input, $v_{R j}$, and the composite of the inputs of capital, labor, energy and materials $\left(K L E M_{j}\right)$ to that sector. In both resource-based and non-resource-based industries, input substitutability at the various levels of the nesting structure is controlled by the values of the corresponding elasticities: $\sigma_{K L E M}, \sigma_{K L}, \sigma_{E M}, \sigma_{E}, \sigma_{M}$ and $\sigma_{R}$.

The production function for electric power embodies characteristics of both primary and non-primary sectors described above. The top-down model therefore represents the electricity sector as an amalgam of the production functions in panels A and B. Conventional fossil electricity production combines labor, capital and materials with inputs of coal, oil and natural gas according to the production structure in panel A. Nuclear and renewable electricity are generated by combining labor, capital and intermediate materials with a composite of non-fossil fixed-factor energy resources such as uranium deposits, wind energy and hydrostatic head using a production function similar to that in panel B, but without the fossil fuel composite, $E$. The resulting production structure is shown in panel $\mathrm{C}$, where total output is a CES function of the outputs of the fossil $(F)$ and non-fossil $(N F)$ electricity production sub-sectors. The elasticity of substitution between $y_{F}$ and $y_{N F}$ is $\sigma_{F-N F}>>1$, reflecting the fact that they are near-perfect substitutes. 


\section{A.2 Model Formulation, Numerical Calibration and Solution}

The economy is formulated in the complementarity format of general equilibrium (Scarf 1973; Mathiesen 1985a, b). Profit maximization by industries and utility maximization by the representative agent give rise to vectors of demands for commodities and factors. These demands are functions of goods and factor prices, industries' activity levels and the income level of the representative agent. Combining the demands with the general equilibrium conditions of market clearance, zero-profit and income balance yields a square system of nonlinear inequalities that forms the aggregate excess demand correspondence of the economy (Sue Wing 2004). The CGE model solves this system as a mixed complementarity problem (MCP) using numerical techniques.

The mathematical relations which define the excess demand correspondence are numerically calibrated on a social accounting matrix (SAM) for U.S. economy in the year 2004, using values for the elasticities of substitution (based on Bovenberg and Goulder 1996) and factor supply summarized in Table 2 . The basic SAM is constructed using 2004 Bureau of Labor Statistics data on input-output transactions, BEA data on the components of GDP by industry, and EIA data on the disposition of energy use. The resulting benchmark table was then aggregated according to the industry groupings in Table A.1.

The economic accounts do not record the contributions to the various sectors of the economy of key natural resources that are germane to the climate problem. Sue Wing (2001) employs information from a range of additional sources to approximate these values as shares of the input of capital to the agriculture, oil and gas, mining, coal, and electric power, and rest-of-economy industries. Applying these shares allows the value of 
natural resource inputs to be disaggregated from the factor supply matrix, with the value of capital being decremented accordingly.

The electric power sector in the SAM is disaggregated into fossil and non-fossil electricity production ( $y_{F}$ and $y_{N F}$, respectively) using the share of primary electricity (i.e., nuclear and renewables) in total net generation for the year 2000, given in DOE/EIA (2004). The corresponding share of the electric sector's labor, capital and non-fuel intermediate inputs is allocated to the between non-fossil sub-sector, as is the entire endowment of the electric sector's natural resource. The remainder of the labor, capital and intermediate materials, along with all of the fuel inputs to electricity, are allocated to the fossil sub-sector.

The final SAM, shown in Figure A-2, along with the parameters in Table A-1, specify the numerical calibration point for the static sub-model. The latter is formulated as an MCP and numerically calibrated using the MPSGE subsystem (Rutherford 1999) for GAMS (Brooke et al 1998) before being solved using the PATH solver (Dirkse and Ferris 1995).

\section{A.3 Dynamic Projections and Policy Analysis}

Projections of future output energy use and emissions of $\mathrm{CO}_{2}$ are constructed by simulating the growth of the economy in 2015. To do this we update the economy's endowments of labor and capital and its supply of net imports, and the growth of energysaving technical progress.

To keep the analysis simple we assume that the model's base-year endowments of labor, capital and sector-specific natural resources grow at a common, exogenous rate. 
This is implemented by means of a scaling parameter whose value is specified to increase from unity in the base year at a rate equal to the long-run average annual growth of GDP, 3 percent in the reference case, and varied under uncertainty.

Single-region open-economy simulations require the modeler to make assumptions about the characteristics of international trade and the current account over the simulation horizon. Since trade is not our primary focus, we simply reduce the economy's base-year current account deficit from the benchmark level at the constant rate of one percent per year.

We account for energy use and emissions by scaling the exajoules of energy used and megatons of $\mathrm{CO}_{2}$ emitted in the base year according to the growth in the corresponding quantity indices of Armington energy demand. We do this by constructing energy-output factors $\left(\chi_{E}\right)$ and emissions-output factors $\left(\chi_{C}\right)$, each of which assumes a fixed relationship between the benchmark values of the coal, refined oil and natural gas use in the SAM and the delivered energy and the carbon emission content of these goods in the benchmark year. ${ }^{1}$ The resulting coefficients, whose values are shown in Table A-1, are applied to the quantities of the corresponding Armington energy goods solved for by the model at each time-step. Finally, to project the key future declines in the energy- and emissions-GDP ratios, we reduce the coefficients on energy commodities in the model's cost and expenditure functions. We do this through the use of an augmentation factor whose value declines at the rates of growth of the AEEI assumed in the text.

\footnotetext{
${ }^{1}$ Fossil-fuel energy supply and carbon emissions in the base year were divided by commodity use in the SAM, which we calculated as gross output - net exports. In the year 2000, U.S. primary energy demands for coal, petroleum and natural gas and electricity were 23.9, 40.5, 25.2, and 14.8 exajoules, respectively (DOE/EIA 2004). The corresponding benchmark emissions of $\mathrm{CO}_{2}$ from the first three fossil fuels were 2112, 2439 and 1244 MT, respectively (DOE/EIA 2003). Aggregate uses of these energy commodities in the SAM are 21.8, 185.6, 107.1 and 6.21 billion dollars.
} 
Table A.1. Sectors in the CGE Model

\begin{tabular}{ll}
\hline CGE model sectors & Constituent industries (approximate 2-digit SIC) \\
\hline Agriculture & Agriculture \\
Coal & Coal mining \\
Crude oil \& gas & Crude oil \& gas \\
Natural gas & Natural gas \\
Petroleum & Petroleum \\
Electricity & Electricity \\
Energy-intensive industries & Paper and allied; Chemicals; Rubber \& plastics; Stone, clay \& Glass; Primary metals \\
Manufacturing & Food \& allied; Tobacco; Textile mill products; Apparel; Lumber \& wood; Furniture \\
& \& fixtures; Printing, publishing \& allied; Leather; Fabricated metal; Non-electrical \\
& machinery; Electrical machinery; Motor vehicles; Transportation equipment \& \\
Transportation & ordnance; Instruments; Misc. manufacturing \\
Services & Transportation \\
Rest of economy & Communications; Trade; Finance, insurance \& real estate; Government enterprises \\
\hline
\end{tabular}

Table A.2. Substitution and Supply Elasticities

\begin{tabular}{|c|c|c|c|c|c|c|c|c|c|}
\hline Sector & $\sigma_{K L}{ }^{\mathrm{a}}$ & $\sigma_{E}{ }^{\mathrm{b}}$ & $\sigma_{A}{ }^{c}$ & $\sigma_{R}{ }^{\mathrm{d}}$ & $\eta_{R}{ }^{\mathrm{e}}$ & $\chi_{E}{ }^{\mathrm{f}}$ & $\chi_{C}{ }^{g}$ & \multicolumn{2}{|c|}{ All Sectors } \\
\hline Agriculture & 0.68 & 1.45 & 2.31 & 0.4 & 0.5 & - & - & $\sigma_{K L E M}{ }^{\mathrm{h}}$ & 0.7 \\
\hline Crude Oil \& Gas & 0.68 & 1.45 & 5.00 & 0.4 & 1.0 & - & - & $\sigma_{E M}^{\mathrm{i}}$ & 0.7 \\
\hline Coal & 0.80 & 1.08 & 1.14 & 0.4 & 2.0 & 1.0956 & 0.0969 & $\sigma_{M}^{\mathrm{j}}$ & 0.6 \\
\hline Refined Oil & 0.74 & 1.04 & 2.21 & - & - & 0.2173 & 0.0131 & ${\sigma_{T}}^{\mathrm{k}}$ & 1.0 \\
\hline Natural Gas & 0.96 & 1.04 & 1.00 & - & - & 0.2355 & 0.0116 & & \\
\hline Electricity & 0.81 & 0.97 & 1.00 & 0.4 & 0.5 & 0.2381 & - & \multicolumn{2}{|c|}{ Electricity } \\
\hline Energy Intensive Mfg. & 0.94 & 1.08 & 2.74 & - & - & - & - & $\sigma_{F-N F}^{1}$ & 8 \\
\hline Transportation & 0.80 & 1.04 & 1.00 & - & - & - & - & & \\
\hline Manufacturing & 0.94 & 1.08 & 2.74 & - & - & - & - & & \\
\hline Services & 0.80 & 1.81 & 1.00 & - & - & - & - & & \\
\hline Rest of the Economy & 0.98 & 1.07 & 1.00 & 0.4 & 1.0 & - & - & & \\
\hline
\end{tabular}

${ }^{a}$ Elasticity of substitution between capital and labor; ${ }^{\mathrm{b}}$ Inter-fuel elasticity of substitution; ${ }^{\mathrm{c}}$ Armington elasticity of substitution; ${ }^{\mathrm{d}}$ Elasticity of substitution between KLEM composite and natural resources; ${ }^{\mathrm{e}}$ Elasticity of natural resource supply with respect to output price; ${ }^{\mathrm{f}}$ Energy-output factor $(\mathrm{GJ} / \$) ;{ }^{\mathrm{g}} \mathrm{CO}_{2}$ emission factor (Tons $/ \$$ ); ${ }^{\mathrm{h}}$ Elasticity of substitution between value added and energy-materials composite; ${ }^{\mathrm{i}}$ Elasticity of substitution between energy and material composites; ${ }^{j}$ Elasticity of substitution among intermediate materials; ${ }^{\mathrm{k}}$ Elasticity of output transformation between domestic and exported commodity types; ${ }^{1}$ Elasticity of substitution between fossil and non-fossil electric output. 